\title{
THE FUNCTIONAL ASPECT OF ASSESSING THE LANGUAGE FOR SPECIFIC PURPOSES AT LAW DEPARTMENTS
}

(C) 2017

\author{
Vikulina Olga Vladimirovna, senior lecturer of Foreign Languages for Humanities Department \\ Petrozavodsk State University (Petrozavodsk, Russian Federation)
}

Abstract. The paper analyzes an evaluation system of law students' LSP level that is developed and introduced by the author in Petrozavodsk State University. The development of such an evaluation system is determined by the necessity of making the assessment of law students' foreign language competence more systematic, objective, communicative, individualized, covering all language skills, less stressful and including self-evaluation. The paper draws attention to the functional aspect of the evaluation system as the functions of the assessment are responsible for the correct arrangement of testing, evaluation impact on the learning process, students' motivation, grading and skills development by means of testing procedures. The author visually presents the application of the assessment functions at different stages of the learning process and their role in entry, formative, progress achievement and summative assessment. The paper also examines other aspects of the evaluation system - aims, developed skills and evaluation criteria.

Keywords: assessment; evaluation; foreign language; language level; language ability; language skills; professional communication; ESP; LSP; communication skills; competence; law; lawyer; university student.

УДК 372.853

\section{ИСПОЛЬЗОВАНИЕ МНЕМОТЕХНИКИ ПРИ ЗАПОМИНАНИИ УЧАЩИМИСЯ ФИЗИЧЕСКИХ ВЕЛИЧИН И ФОРМУЛ}

(C) 2017

\author{
Винокурова Розалия Петровна, учитель физики \\ Сулгачинская средняя общеобразовательная школа им. Константинова И.И. - Дэлэгээт Уйбаан \\ (с. Сулгаччы, Сулгаччинский наслег, Республика Саха (Якутия), Российская Федерачия)
}

\begin{abstract}
Аннотаџия. В данной статье рассматривается вопрос использования мнемотехники-визуализации при запоминании учащимися физических величин и формул в средней школе. Визуализация заключается в том, что каждая физическая величина представлена в виде рисунка, ассоциативно связывающего обозначение с понятием физической величины. К букве, обозначающей физическую величину, дорисованы детали, которые указывают на область применения величины. В статье приведены примеры применения разработанных учителем компьютерных слайдов с анимацией и табличного способа моделирования при повторении. Значимость данной работы заключается в том, что ее использование при изучении физических величин и формул помогает отстающим учащимся эффективно запомнить величины и формулы, а успевающим - систематизировать и закрепить усвоенное. Исследования усвоения материала учащимися при использовании мнемотехники, проведенные в школе, показывают, что коэффициент корреляции 2,9 имеет положительный знак. Это свидетельствует о прочной связи между показателями. При использовании мнемотехники значительно повышается степень запоминания обучающимися физических величин, что способствует качественному усвоению ими основных разделов физики. Разработанная система эффективного запоминания физических величин и формул может быть использована в школах различного типа.

Ключевые слова: мнемотехника; мнемоника; физические величины; физические формулы; физический смысл; основной государственный экзамен (ОГЭ) по физике; единый государственный экзамен (ЕГЭ) по физике; мнемотехника-визуализация; запоминание; соединение образов; повышение эффективности презентации; учебный слайд; методики развивающего обучения; ассоциативный ряд.
\end{abstract}

В связи с введением в средних школах Федерального государственного образовательного стандарта (ФГОС) все актуальнее становится проблема разработки и использования методик развивающего обучения, направленных на усвоение учениками большего объема знаний при обучении физике. Известно, что «язык физики - это язык физических величин, на основе использования которых формулируются и законы, и принципы, и теории» [1]. В школьном курсе физики с 7 по 11 классы учащиеся должны запомнить более ста формул, связывающих физические величины. При обозначении физических величин традиционно используются латинские и греческие буквы. При этом одна и та же буква в разных разделах физики может обозначать различные физические величины, поэтому учащиеся должны знать и единицы измерения величин. Большое значение имеет знание физического смысла величин, что в дальнейшем способствует усвоению учащимися смысла физических законов, процессов и явлений. По результатам многолетних наблюдений можно сделать предположение, что многие ученики испытывают наибольшие затруднения в запоминании именно физических величин и формул. Задача учителя состоит в том, чтобы помочь своим ученикам в этом, потому что без знания обозначений, единиц и физического смысла величин они не смогут оформить краткую запись задачи, найти правильную формулу и решить эту задачу. Ведь, по сути, физические величины - это «алфавит» физики, а без него познать физику невозможно. Проблема эта не нова, не единична и встречается во многих российских школах.

Иногда на уроках физики при подготовке к экзаменам или контрольным работам возникает необходимость быстро повторить материал, пройденный в предыдущих классах. Из опыта преподавания физи- 
ки в средней школе мы знаем, что только постоянные повторения величин ведут к хорошему результату. Наряду с этим можно констатировать, что в имеющихся ныне учебно-методических комплексах (УМК) и результатах опытно-экспериментальной работы (ОЭР) образовательных учреждений, работающих в режиме экспериментальных площадок, к сожалению, нет средств для быстрого и системного повторения физических величин. Чтобы решить эту проблему, мы поставили перед собой задачу найти наиболее оптимальный и действенный способ для эффективного запоминания учащимися физических величин. При этом мы решили воспользоваться проверенным ассоциативным способом, суть которого при запоминании новых величин сводится к применению ассоциаций с уже известными величинами (например, для запоминания шестизначного номера телефона можно воспользоваться такими ассоциациями, как дата и год рождения родных и близких людей, их возраст, год поступления в школу и т.п.) [2]. Эта методика существует давно и называется мнемотехникой. По сути, мнемотехника (или мнемоника) - от греч. mnemonikon - это искусство запоминания, означающее совокупность приемов и способов, облегчающих запоминание и увеличивающих объем памяти путем образования искусственных ассоциаций [3].

Проведенный нами анализ научной и учебнометодической литературы, а также электронно-образовательных ресурсов и др. информационных источников сети Интернет, таких, например, как публикация М. Зиганова, В. Козаренко [3], показал недостаточность практического опыта системного применения мнемотехники-визуализации при запоминании учащимися физических величин и формул. Поэтому целью нашей статьи является исследование процесса усвоения материала учащимися при использовании мнемотехники-визуализации для изучения ими физических величин и формул. Если ранее нами для обучения использовались бумажные карточки с записанными обозначениями физических величин, которыми пользуются многие учителя, то в настоящее время на замену им пришли современные компьютерные технологии и, конечно же, программа подготовки и просмотра презентаций Microsoft PowerPoint.

Для повышения эффективности использования мнемотехники-визуализации необходимо также учитывать то обстоятельство, что современные ученики - это дети, привыкшие к динамической цветности и плохо воспринимающие статичное черно-белое. Поэтому мы стали использовать в своей работе объединение мнемотехники-визуализации, анимации и табличного метода обработки информации для того, чтобы создать эффективный способ запоминания физических величин. Нами созданы и используются для каждой величины рисунки, ассоциативно связывающую букву, её обозначающую, с самим понятием физической величины. В результате мы получили ассоциативный ряд, часть которого приведена на рис. 1: путь на нём изображен в виде извилистой дороги внутри буквы $\mathrm{S}$, время - это часы с буквой $\mathrm{t}$, скорость - бегущий человек в виде буквы v, плотность - ёмкость, в которую налиты вода и масло, масса - буква m, поднимающая гирю, высота - это буква h на крыше многоэтажного дома, сила - мускулистая рука с буквой F, давление - буква $\mathrm{p}$, обутая в валенки с лыжей на одной ноге, энергия - конфета с буквой Е и т.д.

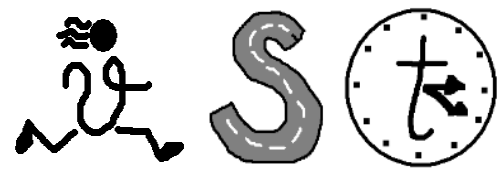

Рисунок 1 - Пример ассоциативного ряда

для запоминания учащимися физических величин

При обозначении некоторых величин нами используются буквы с добавлением некоторых деталей, указывающих на область использования величины. Каждая величина и её единица измерения размещаются на отдельных слайдах, используется анимация для того, чтобы показать физический смысл величин. Разработаны презентации по каждому разделу физики с 7 по 9 классы и за курс 10-11 классов. Слайды объединены по темам, имеются гиперссылки для быстрого повторения. Созданные таким образом презентации мы используем уже более 5 лет при изучении новых величин, повторении и для подготовки к ОГЭ и ЕГЭ. Презентации удобно использовать при изучении новых величин. При повторении учащийся может ответить устно, а может отвечать и при помощи карточек. Также при повторении или тестировании применяется алгоритм работы, смысл которого состоит в изображении на бумаге таблиц с пустыми ячейками или использовании готового шаблона. При этом демонстрируется слайд, учащиеся записывают название, вид и единицу измерения величины в таблицу и сразу же проверяют полученный результат, или отдельно проверяются знание обозначения величины и знание единицы измерения. Затем проверяется то, что ученики запомнили при чтении формул, для чего учитель записывает формулу, а учащиеся либо читают, либо записывают на листочках названия величин.

Нами также разработаны рабочие тетради для учеников 7-9 классов для повторения физических величин и формул с критериями оценивания, которые мы рекомендуем использовать в комплексе с презентациями физических величин. При составлении рабочих тетрадей использован табличный метод моделирования. Ниже приведены примеры таких таблиц:

\begin{tabular}{|l|c|c|}
\hline $\begin{array}{c}\text { Название } \\
\text { величины }\end{array}$ & $\begin{array}{c}\text { Обозначение } \\
\text { величины }\end{array}$ & $\begin{array}{c}\text { Единица } \\
\text { измерения }\end{array}$ \\
\hline Скорость & & \\
\hline & $\mathrm{S}$ & $\mathrm{c}$ \\
\hline & & \\
\hline плотность & $\mathrm{V}$ & кг \\
\hline & & \\
\hline сила & $\mathrm{P}$ & \\
\hline & & \\
\hline жесткость & & \\
\hline удлинение & & \\
\hline
\end{tabular}

\begin{tabular}{|c|c|c|c|}
\hline $\begin{array}{l}\text { Название } \\
\text { величины }\end{array}$ & $\begin{array}{c}\text { Обозначение } \\
\text { величины }\end{array}$ & $\begin{array}{c}\text { Единица } \\
\text { измерения }\end{array}$ & $\begin{array}{l}\text { Фор- } \\
\text { мула }\end{array}$ \\
\hline скорость & $\mathrm{V}$ & & \\
\hline путь & $\mathrm{S}$ & & \\
\hline время & $\mathrm{t}$ & & \\
\hline плотность & $\rho$ & & \\
\hline объем & V & & \\
\hline мacca & $\mathrm{m}$ & & \\
\hline сила тяжести & $\mathrm{F}$ & & \\
\hline мacca & $\mathrm{m}$ & & \\
\hline
\end{tabular}




\begin{tabular}{|c|c|}
\hline $\begin{array}{l}\text { постоянное } \\
\text { число }\end{array}$ & $\mathrm{g}$ \\
\hline вес тела & $\mathrm{P}$ \\
\hline мacca & $\mathrm{m}$ \\
\hline $\begin{array}{l}\text { постоянное } \\
\text { число }\end{array}$ & $\mathrm{g}$ \\
\hline сила упругости & $\mathrm{F}$ \\
\hline жесткость & $\mathrm{k}$ \\
\hline удлинение & $\mathrm{X}$ \\
\hline
\end{tabular}

лить искомое и использовать нужную и правильную формулу. Коэффициент корреляции Пирсона определялся нами в соответствии с рекомендациями, изложенными в $[4 ; 5]$ и составил:

$$
\begin{gathered}
R_{a b}=(7 \times 9067,5-202,5 \times 268) / \\
/ \sqrt{\left(7 \times 5993,75-202,5^{2}\right) \times\left(7 \times 11754-268^{2}\right)}= \\
=(63472,5-54270) / \\
/ \sqrt{(41956,25-41006,25) \times(82278-71824)}= \\
=9202,5 / 3151,4=2,9
\end{gathered}
$$

В комплексном использовании описанных нами средств и методов обучения физике заключается суть системы эффективного запоминания физических величин, при этом задания учащимся даются в порядке усложнения по темам учебников «Физика 7, 8, 9 класс» А.В. Перышкина и др.

Значимость данной разработки заключается в том, что её использование при изучении физических величин помогает отстающим учащимся эффективнее запоминать их, а успевающим - систематизировать и закреплять усвоенное. Образно говоря, тот ученик, который хорошо усвоил и знает физический смысл величин, их обозначение и единицы, может сказать, что у него есть ключ от всех разделов физики и не только.

Исследования и ОЭР по проблеме, вынесенной в заголовок нашей статьи, проводились нами с 2012 по 2015 годы. Каждый учебный год начинался с тестирования учащихся на знание ими единиц физических величин и их обозначений. После использования описанных учебных презентаций всего было проведено 8 тестирований. При этом каждый раз проверялась степень усвоения учениками по 20 физических величин с единицами. Были проанализированы результаты усвоения материала и соотнесены с результаты ЕГЭ, что позволило сделать вывод о чётком проявлении такой закономерности: учащиеся, хорошо запомнившие физические величины, соответственно относительно хорошо сдали и экзамен. Подобные результаты свидетельствуют о том, что запоминание величин учащимися напрямую воздействует на результаты их экзамена по физике, так как, только зная физические величины, можно правильно оформить краткую запись задач, правильно опреде-

$=9202,5 / 3151,4=2,9$
Коэффициент корреляции 2,9 имеет положительный знак - значит, зависимость прямая. Оценка достоверности величины корреляции равна

$$
\chi^{2}=7 \times 2,9^{2}=58,87
$$

и превышает самое высокое значение стандартного коэффициента 10,8, что является наглядным подтверждением прочной связи между показателями. Следовательно, можно сделать вывод о том, что при использовании мнемотехники значительно повышается степень запоминания учащимися физических величин, и это является весомым основанием для повышения качества обучения физике.

В перспективе мы планируем исследовать степень усвоения физических величин и формул учащимися с использованием мнемотехники-визуализации с точки зрения психологии.

\section{СПИСОК ЛИТЕРАТУРЫ:}

1. Гусев В.А. и др. Изучение величин на уроках математики и физики в школе. М.: Просвещение, $1981.79 \mathrm{c}$.

2. Винокурова Р.П. Технология эффективного запоминания физических величин: методическое пособие для учителей физики. Сулгаччы, 2015. 43 с.

3. Зиганов М., Козаренко В. Мнемотехника. Запоминание на основе визуального мышления. М.: Дрофа, 2006. 88 c.

4. Степанова Т.И., Скрябин В.И. Методология педагогического исследования. Якутск: Издательство ЯГУ, 2005. 64 c.

5. Разумовский В.Г. Физика в школе. Научный метод познания и обучение. М.: Гуманитарный изд. центр ВЛАДОС, 2007. $463 \mathrm{c.}$

\section{MNEMONICS USE WHEN MEMORIZING PHYSICAL QUANTITIES AND FORMULAE} (C) 2017

Vinokourova Rozaliya Petrovna, teacher of physics

Sulgachinskaya school named after Konstantinov I.I. - Delegat Uibaan

(Sulgachy, Sulgachinsky nasleg, Republic of Sakha (Yakutia), Russian Federation)

Abstract. This paper discusses the use of mnemonics-visualization when memorizing physical quantities and formulae by high school students. Visualization is represented in the form of a drawing of each physical quantity that is associated with a physical quantity concept. A letter denoting a physical size is accompanied by details that indicate the scope of the variable. The paper contains ways of application of a computer slide show animated presentation and a tabular method of modeling. The importance of this work is explained by the fact that its use for the study of physical quantities and formulae helps lagging students to remember values and formulas effectively. Studies of students mastering the material with the help of mnemonics show that the correlation coefficient of 2,9 is positive. This indicates a strong relationship between the indicators. Mnemonics use significantly increases the degree of memorization of physical quantities by students, hence increases the assimilation of the main sections of physics. This developed system for efficient memorization of physical quantities and formulae can be used in different types of schools.

Keywords: mnemonics; mnemonic; physical quantity; physics formulas; physics; language; mnemonicsvisualization; to remember combination of images; increase; efficiency; presentation; slide; technique; physical; preparation; training; associative array; reflex; association. 